Studia z Dziejów Średniowiecza, t. 23, 2019

\author{
Rafał Kubicki \\ (Instytut Historii, Uniwersytet Gdański) \\ https://orcid.org/ 0000-0002-2171-5713
}

\title{
Dwa przekazy źródłowe dotyczące testamentów z terenu władztwa zakonu krzyżackiego w Prusach (podszpitalnika w Pasłęku z 1453 r. i prokuratora w Lochstädt z około 1476 r.)
}

https://doi.org/10.26881/sds.2019.23.16

Keywords: last wills, Teutonic Order, late medieval Prussia

Dokumenty ostatniej woli spisywane w średniowieczu n terenie Prus Krzyżackich i Królewskich stały się od pewnego czasu przedmiotem bardziej intensywnych badań historyków. Dotychczasowe prace koncentrowały się jednak przede wszystkim na testamentach spisywanych przez mieszczan ${ }^{1}$. Dokumenty takie sporządzali poza nimi również

1 Testamentami mieszczańskimi zajmowali się: E.J. Guttzeit, Das Testament des Matz Berenfelde aus dem Jahre 1505, „Zeitschrift für die Geschichte und Altertumskunde Ermlands" 1962, Bd. 30, s. 425-431; B. Możejko, Gdański mieszczanin $w$ obliczu śmierci. Zapisy testamentowe z II połowy XV w. (Na podstawie księgi ławniczej), „Studia z Dziejów Średniowiecza” 2004, t. 10, s. 127-162; eadem, Rozrachunek z życiem doczesnym. Gdańskie testamenty mieszczańskie $z$ XV i poczatku XVI wieku, Gdańsk 2010, passim; R. Kubicki, Testamenty elblaskie z XIV-poczqtków XVI w. - charakterystyka wraz z lista testatorów w uktadzie chronologicznym, „Rocznik Elbląski” 2006, t. 20, s. 199-208; idem, Mieszkańcy Elblaga w świetle piętnastowiecznych testamentów, „Rocznik Elbląski” 2012, t. 24, s. 25-44; P. Oliński, Społeczne uwarunkowania zapisów testamentowych w średniowiecznym Elblagu [w:] In memoriam honoremque Casimiri Jasiński, red. J. Wenta, P. Oliński, Toruń 2010, s. 181-192; J. Tandecki, Die mittelalterlichen Thorner Bürgertestamente als Ego-Dokumente [w:] Selbstzeugnisse im polnischen und deutschen Schrifttum im Spätmittelalter und in der Frühen Neuzeit (15.-18. Jahrhundert), hrsg. v. R. Skowrońska, H. Flechenecker, R. Czaja, S. Roszak, J. Tandecki, Toruń 2014 (,Studienreihe der polnischen historischen Mission”, Bd. 1), s. 65-83; R. Kubicki, W trosce 
duchowni (biskupi, kanonicy i plebani) ${ }^{2}$ oraz przedstawiciele zakonu krzyżackiego, zarówno osoby sprawujące różne funkcje w ramach korporacji, jak i działające na jej zlecenie. W tym miejscu prezentujemy dwa przekazy źródłowe tego typu, pochodzace z drugiej połowy XV w., dotyczące podszpitalnika w Pasłęku i prokuratora w Lochstädt.

Problem zasad spisywania i funkcji testamentu jako narzędzia prawnego, służącego rozporządzaniu majątkiem przez urzędników krzyżackich, nie doczekał się dotychczas opracowania. Co więcej, w wypadku braci rycerzy w ogóle dysponujemy bardzo nielicznymi wzmiankami o istnieniu tego rodzaju dokumentów ${ }^{3}$.

o zbawienie - testamenty kupców Gdańska i Elblaga z drugiej połowy XV i poczatku XVI wieku, „Przegląd Zachodniopomorski” 2016, R. 31, z. 1, s. 111-128.

2 Edycje testamentów biskupów zawierają kodeksy dyplomatyczne: Urkundenbuch des Bisthums Culm (dalej: UBC), hrsg. v. C.P. Woelky, Bd. 1-2, Danzig 1885-1887, nr 302, s. 229-230, nr 412, s. 318-320, nr 426, s. 330-333; Codex diplomaticus Warmiensis oder Regesten und Urkunden zur Geschichte Ermlands (dalej: CDW), Bd. 3, hrsg. v. C.P. Woelky, Braunsberg-Leipzig 1874, nr 497, s. 508-509; Urkundenbuch des Bisthums Samland, hrsg. v. C.P. Woelky, H. Mendthal, Leipzig 1891-1905, nr 542, s. 365-366; GSPK, XX. HA, OBA, nr 19027. Podobnie jest w przypadku dokumentów ostatniej woli kanoników (edycje testamentów i wzmianki o nich): CDW, Bd. 1, hrsg. v. C.P. Woelky, J.M. Saage, Mainz 1860, nr 195, s. 333-337; Bd. 3, nr 89, s. 59-65; nr 414, s. 401-403; nr 494, s. 501-503; nr 606, s. 601; Bd. 4, hrsg. v. V. Röhrich, F. Liedtke, H. Schmauch, Braunsberg 1935, nr 265, s. 299-301; nr 511, s. 536-537; F. Hipler, Meister Thomas Werner, Domcustos von Ermland und Professor der Theologie in Leipzig, „Pastoralblatt für die Diözese Ermland” 1885, Jg. 17, s. 54-59; H. Haßbargen, Das Testament des Danziger Offizials Nicolaus Schwichtenberg, „Mitteilungen des Westpreussischen Geschichtsvereins” 1926, Jg. 25, H. 4, s. 78-94. Wzmianki o testamentach plebanów i ich edycje: PrUB, Bd. 3/1, hrsg. v. M. Hein, Königsberg 1944, nr 542, s. 413-414; PrUB, 6/1, hrsg. v. K. Conrad, Marburg 1986, nr 393, s. 217; CDW, Bd. 3, nr 317, s. 291; UBC nr 475, s. 378-380; Księga czynszów fary chetmińskiej (1435-1496), wyd. Z.H. Nowak, J. Tandecki, Toruń 1994 (Fontes TNT, nr 78), nr 30; Księga ławnicza nowego miasta Torunia (1387-1450) (dalej: KŁNMT), wyd. K. Ciesielska, Toruń 1973, (Fontes TNT nr 63), nr 1302-1303, 1317, 2305; Handfesten der Komturei Schlochau, bearb. v. P. Panske, Danzig 1921 („Quellen und Darstellungen zur Geschichte Westpreussens”, 10), nr 189, s. 198-199; APG, Akta miasta Elbląga, „rękopisy elbląskie”, 492/467, s. 554; Das Röseler Pfarrbuch. Aufzeichnungen der Kirchenväter an der Pfarrkirche zu Rösel in den Jahren 1442-1614, hrsg. v. G. Matern, Braunsberg 1937, s. 22, 67, 84, 104, 106, 107; GSPK, XX. HA, OBA nr 29020, nr 20549, nr 21842.

3 Znany jest testament brata zakonu niemieckiego Wernera Overstolza z 1443 r., GSPK, XX. HA, OBA nr 8308. W inwentarzu listów zakonnych, przechowywanych w Tajnym Archiwum Pruskich Dóbr Kultury w Berlinie Dahlem, odnotowano także testament spisany w 1453 r. przez brata rycerza Mikołaja (Nicklis) Penewitcza z Pasłęka (ten sam regest w opisie dwóch jednostek: GSPK, XX. HA, OBA nr 12000 i 28907). W trakcie kwerendy prowadzonej w 2014 r. w obu wskazanych jednostkach inwentarzowych nie odnaleziono niestety wspomnianego dokumentu. Według notatki 
W tym kontekście ciekawy jest przypadek pierwszy, dotyczący ostatniej woli podszpitalnika w Pasłęku Hansa Osterreicha, który przesłał do pisarza wielkiego mistrza zakonu projekt zapisów przygotowywanego testamentu ${ }^{4}$. Z treści listu wynika, że całość zatwierdzał wielki mistrz, a szczegółowe dyspozycje, dołączone w spisie kolejnych postanowień, które powinny znaleźć się w testamencie, miały ścisły związek z pozycją społeczna podszpitalnika i jego działalnościa na rzecz korporacji zakonnej ${ }^{5}$. Swiadcza o tym przede wszystkim te zapisy, które dotyczyły pobożnych fundacji, w tym ufundowania czuwań i mszy przede wszystkim za dusze dwóch wielkich mistrzów zakonu krzyżackiego: Pawła von Russdorfa i Konrada von Erlichshausena. Omawiany przekaz przynosi jednocześnie ciekawe informacje na temat zabezpieczenia podstaw mterialych fukcjonoania szpitala (zakup czynszów) oraz zobowiązań modlitewnych o charakterze memoratywnym sprawowanych w intencji różnych osób przez związanych z nim przedstawicieli niższego duchowieństwa. Wspomina także między innymi o księdze zmarłych prowadzonej w szpitalu (,todenbuch des spittales”).

archiwisty brak dokumentu stwierdzono już 28 VI 1984 r. (zapiska na okładce jednostki OBA nr 12000).

4 Niewiele wiadomo o postaci Hansa Osterreicha. Funkcję szpitalnika (,Spittler”) objął on dożywotnio z woli wielkiego mistrza Pawła von Russdorfa w 1440 r., GSPK, XX. HA, OBA nr 7729; RHD, Bd. 1/1, nr 7729, s. 481. Idąc za tą informacja, Krollmann przypuszczał, że Hans Oesterreich nie był członkiem zakonu krzyżackiego, zob. C. Krollmann, Das Heilige-Geist-Hospital zu Pr. Holland im Mittelalter, „Altpreußische Monatsschrift" 1917, Bd. 53, s. 472. Zauważmy, że w publikowanym tu liście z 1453 r. Hans sam określił się jako podszpitalnik w Pasłęku (,undirspittaler zcu Holland”). Wynikało to z faktu, że szpital w Pasłęku podlegał bezpośrednio komturowi w Elblagu, pełniącemu jednocześnie funkcję wielkiego szpitalnika, zob. Ch. Probst, Helfen und Heilen. Hospital, Firmarie und Arzt des Deutschen Orden in Preussen bis 1525, Bad Godesberg 1969, (,Quellen und Studien zur Geschichte des Deutschen Ordens”, 29), s. 69. Choć konsultacje w sprawie spisania testamentu odbyły się w 1453 r., to Hans Oesterreich żył jeszcze w 1458 r., gdy miał wystawić przywilej dla wsi Ławice (niem. Hansdorf), zob. G. Conrad, Preuss. Holland einst und jetzt, Pr. Holland 1897, s. 252; J. Rink, Die christliche Liebestätigkeit im Ordenslande Preußen bis 1525, Breslau 1911 , s. 58.

5 Ogólnie na temat funkcji podszpitalnika, który odpowiadał za sprawy opieki duchowej i fizycznej nad chorymi w szpitalu, nadzorując kapłanów, półsiostry i wolontariuszy zob. P.G. Thielen, Die Verwaltung der Ordensstaates Preussen vornehmlich im 15. Jahrhundert, Köln-Graz 1965, s. 75, 109. 
Z kolei materiały odnoszące się do prokuratora ${ }^{6}$ w Lochstädt Hansa von Köckeritz ${ }^{7}$ z 1476 r. zawierają obok testamentu również inwentarz opisujacy nie tylko zamek, ale i całe prokuratorstwo w Lochstädt $^{8}$. Pierwszy przekaz przybliża samą procedurę spisywania testamentów przez osoby sprawujące urzędy z woli zakonu krzyżackiego, co wymagało akceptacji wielkiego mistrza zakonu. Oba przynoszą też szczegółowe informacje na temat majątku osobistego wspomnianych osób oraz kręgu ich współpracowników, otoczenia społecznego i kontaktów gospodarczych, szczególnie w wypadku prokuratora i zamku w Lochstädt. W związku z tym mogą być wykorzystane w dalszych badaniach dotyczących funkcjonowania osób piastujących urzędy w ramach zakonu (prokurator) lub pod jego nadzorem (podszpitalnik) oraz praktyki odnośnie do posiadania i rozporządzania przez nie majątkiem osobistym. Przy okazji potwierdzają też fakt odnotowywany i w innych przekazach, że w drugiej połowie XV w. już nie egzekwowano względem braci rycerzy obowiąującej w zakonie zasady ubóstwa9 .

Przygotowując do druku wskazane przekazy, korzystano częściowo z instrukcji wydawniczej Adama Wolffa i Johannesa Schultze $^{10}$. Przyjęto zasadę zachowania, w miarę możliwości, oryginalnej pisowni źródła. Ingerencja wydawcy ograniczyła się do zapisu liter zgodnie z ich wartością fonetyczna, dokonano więc zamiany „v” na „u”

6 Ogólnie na temat funkcji i zakresu obowiązków prokuratora w zakonie krzyżackim zob. P.G. Thielen, Die Verwaltung..., s. 27, 95-96.

7 Niewiele wiemy o postaci wspomnianego prokuratora w Lochstädt. Jeszcze 26 IV 1476 r. Hans von Köckeritz wystawił dokument nadania 4 mórg ziemi dla karczmarza w Camstigal, GSPK, XX. HA, Pergament-Urkunden, Schiebl. XLIII 42/3; RHD, Bd. 2, nr 3390, s. 376-377. Zmarł zaś 15 XI 1476 r., Amtsträger des Deutschen Ordens in Preußen und in den Kammerballeien des Reiches (oberste Gebietiger, Komture, Hauskomture, Kumpane, Vögte, Pfleger, Großschäffer), zusammengestellt und indiziert von D. Heckmann, Werder 2014, s 103, http://www.hiko-owp. eu/wp-content/ uploads/2015/11/Amtstr\%C3\%A4ger-DO-Preu\%C3\%9Fen.pdf (dostęp: 3.03.2019).

8 Wspomniany inwentarz, który tu pomijamy, został już opublikowany w Das Grosse Ämterbuch des Deutschen Ordens, hrsg. v. W. Ziesemer, Danzig 1921 (dalej: GA), s. 48-49.

9 Na temat prób przywrócenia zasad ubóstwa braci rycerzy i dyscypliny wewnętrznej zakonu w drugiej połowie XV w. za pomoca wizytacji zob. M. Biskup, Plany reformy zakonu krzyżackiego w Prusach z 1492 roku [w:] Prusy - Polska - Europa, red. A. Radzimiński, J. Tandecki, Toruń 1999, s. 278-279.

10 A. Wolff, Projekt instrukcji wydawniczej dla pisanych źródet historycznych do połowy XVI wieku, SŹ 1957, t. 1, s. 155-184; J. Schultze, Richtlinien für äußere Textgestaltung bei Herausgabe von Quellen zur neueren Geschichte, „Blätter für die Deutsche Landesgeschichte" 1962, Bd. 98, s. 1-11. 
oraz „w” na „u” (np. und zamiast vnd, uff zamiast wff). Ujednolicono również pisownię wielkich i małych liter w ten sposób, że wielka literą zapisano jedynie imiona i nazwiska, nazwy świąt kościelnych oraz nazwy miejscowości. W celu ukazania podstawy źródłowej użyto następujących symboli z instrukcji: /- -/ skreślenie, [s] potwierdzenie błędu lub indywidualizacji zapisu w podstawie wydania, (?) watpliwość. Abrewiacje rozwiązano bez zaznaczania tego w tekście. Występujące $\mathrm{w}$ tekście oryginalnym cyfry rzymskie zastapiono arabskimi bez sygnalizowania tego $\mathrm{w}$ przypisach. Ujednolicono również zapis jednostek obrachunkowych, stosując skrót: mr. - mark (grzywna). Oszczędność miejsca w druku zadecydowała o nieoddawaniu oryginalnego układu tekstu, lecz zastapieniu go wprowadzonym przez wydawcę uporządkowaniem graficznym. W dokumencie drugim znakiem: | oznaczono koniec wiersza ${ }^{11}$.

\section{Aneks źródłowy}

1

Pastęk, 7 VI 1453 r.

List podszpitalnika w Pastęku Hansa Osterreicha do pisarza wielkiego mistrza Augustyna w sprawie treści dokumentu jego ostatniej woli. W załaczeniu Hans przesyta do zatwierdzenia przez wielkiego mistrza zakonu postanowienia, które maja być zawarte w jego testamencie.

Oryg.: GSPK, XX. HA, OBA $n r$ 12092, $k$. $1 r-2 v$.

Reg.: RHD, Bd. I/1, nr 12092.

Uw.: karty papierowe o wymiarach $31 \times 22 \mathrm{~cm}$. Sygnatura dawna LIII 82.

Meyner garfruntlichen grus zcuvor und was ich euch zcu willen kan gethun zcu allen czeiten. Lieber her schreiber noch deme alls ichs mit ouch gelossen habe die artikeln, die do sullen stehen in dem testaments brieffs, das ich euch die welde clerlich inschrifften senden.

11 Odrębnych badań wymaga kwestia kart papieru użytych do spisania prezentowanych dokumentów. W tym ustalenia, czy występują na nich znaki wodne wskazujące na jego proweniencję. 
Also sende ich euch die nu in dissen brieffe vorslussen und bitte euch, das eer wol wollet thun und woldet disse artikel /-von-/ meynen gnedigen herren dem homeister vorbrengen und een lossen lesen ee denne, das eer sie in den brieff schribet, wen ich etczliche artikel mehe habe gesatcz denne ${ }^{a-}$ vor $^{-a}$ und nemlich die letczten czwene und das eer woldet meynen gnedigen herren bitten, ap her etczwas dorinne vorde vynden, das do zcu vil addir czu wenig were geschreben, das her das wolde lossen wandeln noch seynen willen alleyne, das der testaments brieff yo behalde und beslisse die meynunge disser artikel uff das zcu langen czeiten der an nicht hindernisse ${ }^{b}$-mogen ${ }^{-b}$ komen, wen ich disselbige och dissen beweiss befolen habe/-n-/, namentlichen meynen gnedigen herren zcu vorczelen und bitte euch, das eer wol wollet thu ${ }^{\mathrm{e}} \mathrm{n}$ und wollet mir den brieff senden mit dissen beweiser, der sal euch euwer gelt von meynt wogen geben, wen ich alle tage meyner sorge habe und sie kome her czu die mich meynen und dorummo so wolde ich gerne dis testament zcu puncten brengen die weile ich lebete das wil ich gerne vorschulden, wo ich kan. Gegeben zcu Hollant am achtentage des Heiligen Lichnams im LIII'ten jore.

Hans Osterrich undirspittaler zcu Holland

[in dorso:] Dem wolwissenden und kunftigen manne Augustino ${ }^{1}$, des erwirdigen homeisters schriber, meynen besundern frunde und gunner ane seumen mit aller fruntschafft.

[k. 2r] Disse nochgeschreben artikel sal innehalden der testaments brieff des undirspittalers zcu Hollant.

Der erste artikel ist der, das Hans Osterreich mit wissen und willen des homesiters hot gekofft /-meynen ewigen testamente-/ 7 1/2 gute mr. czins uff eynen widderkouff zcur Cleynen Wickeraw ${ }^{2}$ dor obir her denne hot des homeisters vorsegilte brieff, welche czinsser gesellig syn alle jor jerlich uff der Heilgen Dri Konige tag.

Item zcu demselbigen testamente hot her Niclus Brand, der alde pfarre von Herssefelt ${ }^{3}$, och gegeben 3 gute mr. pfenig czins, den her hot gekoufft uff Hans und Gunthery guter zcu Hoendorffe ${ }^{4}$, welche czinser gefelig seyn uff Unser Lieben Frauen tag eer gebort dor obir ${ }^{c}$ her-c $^{-c}$ denne hot eynen vorsegilten brieff vom kompthur zcu Cristburg ${ }^{5}$ und och mit Hans und Gunthers angehangen ingesegil, welchin sulchen brieffe der vorgeschreben her Niclus mir Hans Osterrich itczunt hot uffgegeben bye dem testamente zcu bliebende. 
Item disser vorgeschreben czinss in der summa ${ }^{d \text {-ist }}{ }^{-d} 101 / 2$ gute mr., ${ }^{e-d i e^{-e}}$ haben die egedochten her Niclus Brand und Hans Osterrich mit wissen und willen des homeisters gegeben zcu eynen ewigen testamente, die weile der houptstam disses czinss weret.

Item disseselbigen czinsser sal derselbige Hans ${ }^{f}$ Osterrich $^{-f}$ adir seyne nochkomelinge alle jor jerlich eymanen uff eren czins tag alls die brieffe, die derobir seyn gegeben lauthen und innehalden.

Item und von denselbigen 10 1/2 mr. czinses sal Hans Osterrich adir seyne nochkomelinge alle jor jerlich geben den acht pristern im spittale zcu Holland alzo dem pfarrer der krancken im selbigen spittale und den anderen seben vicarien, die eer leen im selbigen spittale haben itczlichem eyne gute mr. uff den tag Nativitatis Marie.

Item vor sulch gelt sullen die acht prister alle vier wochen im jore im spittale zcu Hollant noch der moltczeit, uff welchen tag ys een bequeme wirt seyn, syngen eyne gantcze vilge [s] und des anderen tages des morgens sal der vorgedochte pfarrer im selbigen spittale syngen eyne zelemesse mit vier schulern und die anderen seben vicarien sullen desselbigen morgens lezen och itczlicher eyne zelemesse do zcu sich och eyn itczlicher sal schicken noch seynen besten vormogen und sullen fleislichen bitten vor her Conrad von Erlichshaussen ${ }^{6}$ zele, der do homeister ist nest vorsterben, und vor her Paul Rusdorffs ${ }^{7}$ zele und och vor die uns so wir von hynnen seyn gescheiden und vor alle unsers ordens lieben bruder zelen und och nemlich vor Hans Osterrichs zele und her Niclus Brands zelen, so die von hynnen seyn gescheiden und vor Withhards Struloen zele des guter eyn ${ }^{g}$ teyles $^{-g}$ zcu dissen testamente och seyn gekomen und vor alle lieben zelen, die us dem spittale zcu Holland seyn vorscheiden und dem spittale eer guter hoben bescheiden, welchen dissen vorgeschreben zelen und allen cristgeloubigen zelen zcu hulfe und zcu troste dis testamente ist gestifftet.

Item do bouen sullen dieselbigen acht prister zcu vier molen im jore alse noch itczlicher quatemper och syngen eyne gantcze vilge und der pfarrer sal och des anderen tages syngen eyne zelemesse mit den vier schulern und itczlich prister sal och lesen eyne zelemesse in der obengeschreben weise und sullen fleislich bitten vor her Niclus Brants zele so her verstirbet und vor seyner eldern zelen und vor alle lieben zelen, die us seyme slechte vorscheiden seyn und och die eem yrkeyn gethan haben.

Item der egedachte pfarrer sal alle disse vorgeschreben zelen, die do seyn itczunt verstorben und noch von hynnen werden 
${ }^{h}{ }^{-}$vor $^{-h}$ scheiden schriben in das todenbuch des spittales ewig dorinne zcu bliben und sal zcu allen dissen vorgeschreben messen noch dem ewangelio vor sie offentlich bitten und das kegenwertige volk vormanen, das sie och vor sie und vor alle cristglobige selen flislichen bitten.

Iten so sal der egedochte Hans Osterrich adir seyne nochkomelingen von den obengeschreben $101 / 2 \mathrm{mr}$. alle jor jerlich haben $21 / 2$ gute $\mathrm{mr}$. vor die eyn mannunge disses vorgeschreben czinser und vor das, das her sal besurgen [s] vier wachslichte, die do sullen burnen uff den kertczen bey dem leichczeichen alle die vorgeschreben vilgen und zelemessen obir so man die wirt syngen und eyne zelelicht sal her och besurgen und das sal her lossen zcu allen dissen vorgedochten zelemessen offtragen und lossen oppern noch gewonheit des spittales.

$$
\text { [k. 2v] }
$$

Item och sal der vorgedochte Hans Osterrich adir seyne nochkomelinge von den vorgedochten $21 / 2 \mathrm{mr}$. den vier schulern, die do die zelemessen werden syngen itczlichen schuler von itczlicher messe geben /-vie-/ 4 pfennige.

Item so die vorgeschreben czinser widder werden abegekofft adir abegelost, so sal den vorg[eschrebene] Hans Osterreich addir seyne nochkomelingen den houptstam mit den czinsser zcu eem nemen und noch rothe, wissen und willen eynes kompthurs zcu Elbinge ${ }^{8}$, der zo ${ }^{i} \mathrm{zcu}^{-i}$ getrulich /-zcu-/ sal helfen rothen das ander czinsser gemacht werden, wo man kan do sie gewisse werden seyn und der an sal een och nymant hindern wen wir eem das irlouben uff das dis testament eyne longer bestendike moge haben.

Item och sullen dieselbigen acht prister dissen unsern brieff und ouch die kouffbrieff obir disse vorgeschreben czinser in erer gewalt und bewarunge haben, wen sie alle Hans Osterrich gelobet haben, und sich vorpflicht haben vor eem dis vorgeschreben testament also zcu volfuren und vorbrengen alle die weile, das een sulch gelt wirt gefallen itczlichen eyne gute $\mathrm{mr}$. des jore.

Item so sal Hans Osterrich adir seyne nochkomelinge disses /-obenge-/ brieffe und och der kouffbrieffe haben eyne abeschrifft und mit gantczen fleisse dor an seyn, das dis testament noch der obengeschreben weise veste und steticlich gehalden und volbrocht werde.

Item och ap der egedochte Hans Osterrich adir seyne nochkomelinge addir die prister irkeyn hyndernisse worden haben an dissem testamente, der sal das dem kompthur zcu Elbinge vorbrengen, der sal eem das wandeln ap her kan, kan her das nicht ${ }^{j}$ thun $^{-j}$, so sal 
die sache an uns addir unser nochkomelinge komen, do sal ys eem gewandlit werden.

Item och so hat der egedochte Hans Osterrich mit unserm wissen und willen etczliche vicarien in unserm spittale zcu Holland mit etczlichen czinssern gebessert uff das sie diste lenger bestendiger bliben mogen und dieselbigen czinsser sullen och ewig bey denselbigen vicarien bliben /-glicher weise-/ glichs dem houptcznisse, den sie haben in eren stifftbrieffen.

Item die vicarie/-n-/ Unsir Lieben Frauen uff dem altare hinder der thoer hot her gebessert mit 2 guter $\mathrm{mr} .{ }^{9}$ Item die vicarien uff dem altare /-sente-/ Katherine und Barbare hot her gebessert mit 3 guten mr. Item die vicarie uff dem altare Johannis Baptiste und Ewangeliste hot her gebessert mit 2 guten $\mathrm{mr}$.

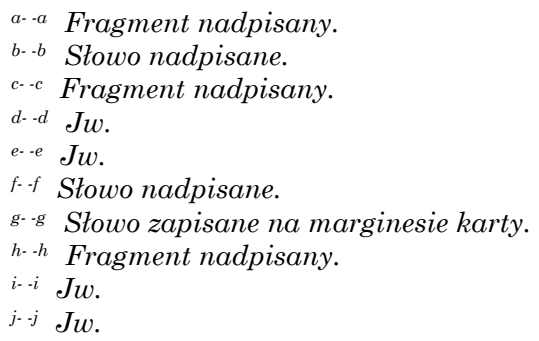

1 Augustyn Wichardi, notariusz i pisarz wielkiego mistrza Ludwika von Erlichshausena, odnotowany w latach 1453-1461, RHD, Bd. I/1, nr 12092, 15283, 15285, 15357, Bd. II, Göttingen 1948, nr 3026, 3034, 3040, 3049, 3051, 3059, 3064, 3070, $3072,3085$.

2 Wikrowo (niem. Klein Wickerau) (zob. P. Germershausen, Siedlungsentwicklung der preussischen Ämter Holland, Liebstadt und Mohrungen vom 13. bis zum 17. Jahrhundert, Marburg/Lahn 1970, nr 312, s. 384-385).

3 Jelonki (niem. Hirschfeld), zob. ibidem, nr 91, s. 209-210.

4 Wysoka (niem. Hohendorf), zob. A. Semrau, Die Siedlungen im Kammeramt Kirsiten (Komturei Christburg) im Mittelalter, „Mitteilungen des Coppernicus-Vereins für Wissenschaft und Kunst zu Thorn” 1933, H. 41, s. 60-65.

5 Komtur w Dzierzgoniu.

6 Wielki mistrz zakonu krzyżackiego Konrad von Erlichshausen (1441-1449) uczynił liczne zapisy dla szpitala, zob. C. Krollmann, Das Heilige-Geist-Hospital..., s. 479.

7 Wielki mistrz zakonu krzyżackiego Paweł von Russdorf (1422-1441) powierzył dożywotnio funkcję szpitalnika w Pasłęku Hansowi Oesterreich, zob. ibidem, s. 472.

8 Komtur w Elblagu.

9 W 1451 r. wieczystą mszę i wikarię ku czci NMP ufundował w szpitalu wielki mistrz zakonu Ludwik von Erlichshausen, zob. ibidem, s. 480. 
[Lochstädt], około $1476 \mathrm{r}^{1}$

Testament prokuratora $w$ Lochstädt Hansa von Köckeritz.

Oryg.: GSPK, OBA, nr 16650, s. 1-4.

Reg.: RHD, Bd. I/2, nr 16650.

Uw.: bifolium papierowe o wymiarach $11,5 \times 33 \mathrm{~cm}$. Sygnatura dawna LVI 30/a.

[s. 1]

Ich bruder Hanns vonn Kokeritcz deussches | ordenns fphleger czu Lowchstete ${ }^{2}$ habe dyss ।

nochgeschrebene testamente bestaldt ap Got | der Here ober mich gebo the uff vorwilli | vunge

unnde vorliebunge meyner oberster. I

Czum irsterm hot her Johanns der pristerhere| bey sich 41 reynissche | goldenn, die ich em oberandtwerdt habe. |

Czum irsstenn szalher Johanns der pristerhere / habenn vonn denn 41 | goldenn, 3 goldenn reynissche. |

Her Peter dem kappalan eynen goldenn unde I peltcz vonn wochss rockerne unde eyn scheffenn | peltcz. |

Denn herenn czu Su${ }^{e}$ ndte Olbrecht ${ }^{3} 2$ golden | czur monsstrantcze. |

Her Wachaw eynen czu loszenn mantel eyne | braune kogel unde daz groe fpherdt den | Trawdelawkenn (?) unde 6 goldenn. |

Dem hoeffemeister 6 goldenn unde dye | bloue schaube, die bloeue kogel unde | einen scheffenn peltcz szal em knorre machen. |

Symon 6 goldenn unde dass groe fphert, | das em der stadtheller gegeben hot, undelein pantczer unde eyn kolner, dass denn | bornssteinmeister ${ }^{4}$ gehordt hot, meyn arenbrost $[s] \mid$ mit der leyer unde kocher unnde dye ne ${ }^{e}$ ue $\mid$ schaube unnde eynen scheffenn peltcz czu | machen unde daz kleyne schaube tysschenn. |

Ouch zo bin ich em schuldigk 2 swekenn | vonn 6 adder $7 \mathrm{mr}$. |

Item Tosszennfelder 3 goldenn unnde dye breune schaube.|

Thomass 3 goldenn unde den men farenn | rogk. |

Nicolaenn 2 goldenn. |

Dem ffysscher 2 goldenn. |

Dem karbesszheren [s] czu Lewchstete 3 goldenn. |

Pawel Mayssawer 4 reynische geldenn / bin ich em schuldig vor dye ochssenn. I 
Diss alhy obengeschrebenn sall der prister | here vonn denn 41 goldenn aussrichtenn.

[s. 2]

Ithem Hannussze dem jungenn 12 unnge | ryssche goldenn, 3 nobbelenn, $8 \mid$ halbe nobbelenn daz sal man dem | grosskompthur ${ }^{5}$ andtwerten mit dem liungenn.

Her Heynnrichch [s] uff der ffirmaneyen / meynen weyssenn mantel. |

Den herenn uff der ffirmayneyen $1 / 2$ thonne | ke ${ }^{e}$ ssze.|

Dem kofent czu Konningessberg ${ }^{6} 1$ thonne $\mid$ ke $^{e}$ ssze unnde 2 thonnen honniging, die | legen alhy im keller. |

Item so habe ich eynen kelglag czu Lawchstete | in der kirche, der szal do bloybenn. |

Item so ist denne eynn czu brachen kellich / widder in der kirche do bitte denne den / heren stadtheler adde eyn czukonnftigen heren | homeister sulchen czu brachenn kellich czu | nemen unnde dy brylle unde daz hillethum, $[s]$ | daz her Johanns der pristerhere bey sich hot, | domitte czuvor wirkenn unde daz czu | setczenn bey sundte Katterinen bilde ${ }^{7}$ |czu Konnigessberg, daz do ouch meyn ist gewest. |

Item Hanns Lybhardt bin ich schuldigk $3 \mathrm{mr}$.| unde 12 schillinge, daz sal em der hauss | kompthur ${ }^{8}$ geben czu Konnigesberg. |

Item so sal man eynem prister czu Konnigessberg| eynen rogk unde eyne kogel gebenn sulchelsal der hausskompthur ouch aussrichten / von dem fpherde unde wass denne ober | rigk bleybet von dem fpherde sal man |czu dem gessindeloen czu Lowchstete haben | uff Michaelis mit dem preusschen gelde | daz czu Lowchsthete vorssegelt ist. |

Item zo bin ich Bernhardt Pynigk schuldigk | blebem [s] $75 \mathrm{mr}$. zo habe |ich seyner frauen, dy tot is, 13 gutte $/ \mathrm{mr}$. Item eynen kellich in der lade, der | hatte 2 1/2 leythyge mr., vor daz oberge | sal man em koren adder wesse gebenn, | dass her vornuget wirdt. |

Item so habe ich genomen von Raffheyl Becker | uff die vorganne wolle ir tucher gewandt, | daz thuch vor $3 \mathrm{mr}$. denn steyn vor $1 / 2 \mid \mathrm{mr}$. was der angebricht sal man em vorgenugenn von der wolle uff den her | best.

[s. 3]

Dye czynnen schusszelen, dy ich habe / in meiner kamer, sullen 8 kenn | Konnigeszberg in den kofent dy ander | sullen czu Lowchstete bleybenn. | 
Item 2 thucher groegewandt sal man | denn gessellen ere nodtdurfft uff denn | winnter telenn, ichlichem 7 elenn, dy | tucher sindt itczundt czu Lowchstete. |

Ouch ist noch 1 stucke gewanndt do sal | man 2 kleydt aussmachen 2 | armenn mensschenn, woe daz stheet | henn czu gebonn. |

${ }^{a}$-Item so sal man den pristern zcu Sandt|Albrechte ${ }^{9}$ lo $^{\mathrm{e}}$ nen vor den salter $[s]$, den | sie sollen lessen. |

Item so sal man den frauen die meyn / warten ouch loenen, waz do mogelich $\mid$ ist. $^{-a} \mid$

Item so ist mir der here bisschoff ${ }^{10}$ schuldig|120 reynissche goldenn, | welch golt ich bitte bey dem slosse czu|Lowchstete czu lossenn unnde iss eynen czu | befelenn, der iss an daz sloss czu Lowchsthete|leget, so dass is in kelgk gedacht worde/unnde sunderlich daz korenn hauss unde|ouch gessullert unde daz is derselbige / dem is befolenn wurde widder vor rechent, wo wor her is aussgebe. I

Item so bin ich widder schuldig dem | herenn bischoffe 2 unngerisschelgoldenn, die sal man an dem obenge schrebenelgelde abesloenn.

[s. 4]

${ }^{b}$-Item Hans Enthreich manet $8 \mathrm{mr}$. von | eyme halben wintter garh do sal| Symon unde Thomas von wissen ${ }^{-b}$. |

${ }^{c}$-Dye czedel (?) von Lochstet was des ist | und das thesstament ${ }^{-c}$

[s. 5-8] wydrukowano w Das Grosse Ämterbuch des Deutschen Ordens, hrsg. v. W. Ziesemer, Danzig 1921, s. 48-49.

a-a Fragment napisany inna ręka.

$b \cdot-b$ Tekst napisany inna ręka.

$c-c$ Jw.

1 Zob. przyp. 7.

${ }^{2}$ Lochstädt (obecnie teren osiedla Pawłowo w granicach administracyjnych Bałtijska, obwód kaliningradzki, Federacja Rosyjska).

3 Kaplica św. Wojciecha (Sankt Albrecht) zbudowana w 1424 r. przez wielkiego marszałka Ludwika von Landsee, późniejszy obszar wsi Tękity (Tenkitten), obecnie Letnoje (obwód kaliningradzki, Federacja Rosyjska). Na temat kaplicy zob. A. Hagen, Ueber die St. Adalberts=Kapelle in Tenkitten, „Neue Preußische Provinzial-Blätter” 1848, Bd. 5, s. 256-270; M. Biskup, W sprawie średniowiecznych pielgrzymów polskich do miejsca zgonu św. Wojciecha na Sambii [w:] Kościót - Kultura - Społeczeństwo. 
Studia z dziejów średniowiecza i czasów nowożytnych, red. S. Bylina et al., Warszawa 2000, s. 19-21.

4 Mistrz bursztyniarski (Bernsteinmeister) z siedzibą na zamku w Lochstädt, zob. P.G. Thielen, Die Verwaltung..., s. 111.

5 Wielkim komturem w latach 1472-1476 był Wilhelm von Eppingen.

6 Konwent zakonu krzyżackiego w Królewcu (obecnie obwód kaliningradzki, Federacja Rosyjska).

7 W kaplicy zamkowej w Królewcu znajdował się ołtarz i wizerunek św. Katarzyny, zob. W. Rozynkowski, Omnes Sancti et Sanctae Dei. Studium nad kultem świętych $w$ diecezjach pruskich państwa zakonu krzyżackiego, Malbork 2006, s. 162.

8 Komtur domowy w Królewcu. W 1471 r. funkcję tę sprawował Georg von Kottenheim, a w 1477 r. odnotowano komtura domowego Erazma von Reitzensteina.

9 Zob. przyp. 3.

10 Biskupem sambijskim w latach 1474-1497 był Johann von Rehewinkel.

\begin{abstract}
Two source texts regarding wills and testemants from the State of the Teutonic Order in Prussia (a spitler in Pasłęk from 1453 and a pleger in Lochstädt from around 1476)
\end{abstract}

The study includes an edition of two source texts from the Secret State Archives Prussian Cultural Heritage Foundation in Berlin-Dahlem (Geheimes Staatsarchiv Preußischer Kulturbesitz) regarding the wills and testaments of a spitler in Pasłęk Hans Osterreich from 1453 and a pfleger in Lochstädt Hans von Köckeritz from around 1476. Unfortunately, preserved source texts of this type are sparse. This is why historians' research into last wills is focused mainly on wills and testaments drawn up by townspeople. Both texts illustrate both the very procedure of drawing up a will and testament by people appointed by the Teutonic Order, which required the approval of the Grand Master (the spitler), as well as specific information about the personal assets of the Order's officials and their social environment (the pfleger). Because of this they could be important for further research into the functioning of the lower offices of the Order and the changes in the way of enforcing the principles of the possession and management of personal property by people serving these functions. 